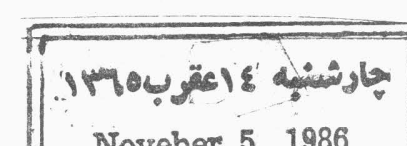 Noveber 5, 1986

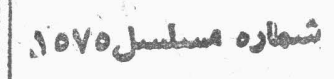 \\ حقيقت النقلابو \\ ا
}

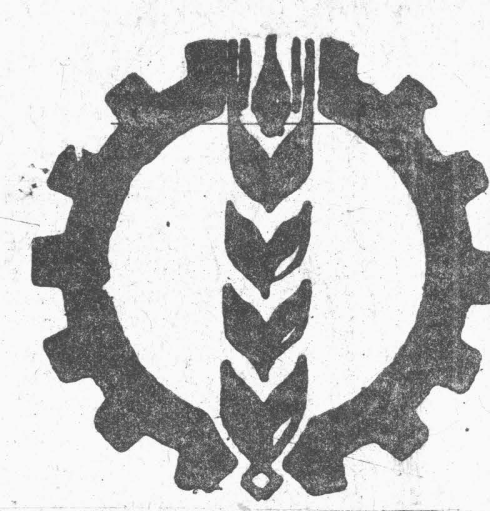

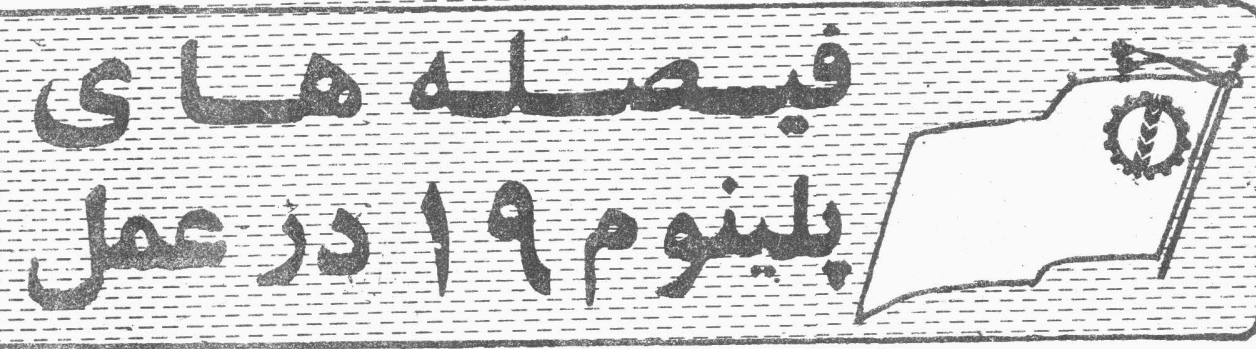

بيجج ز حمنكستـا نو

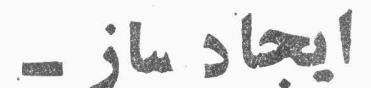
ها نهاي اوليه

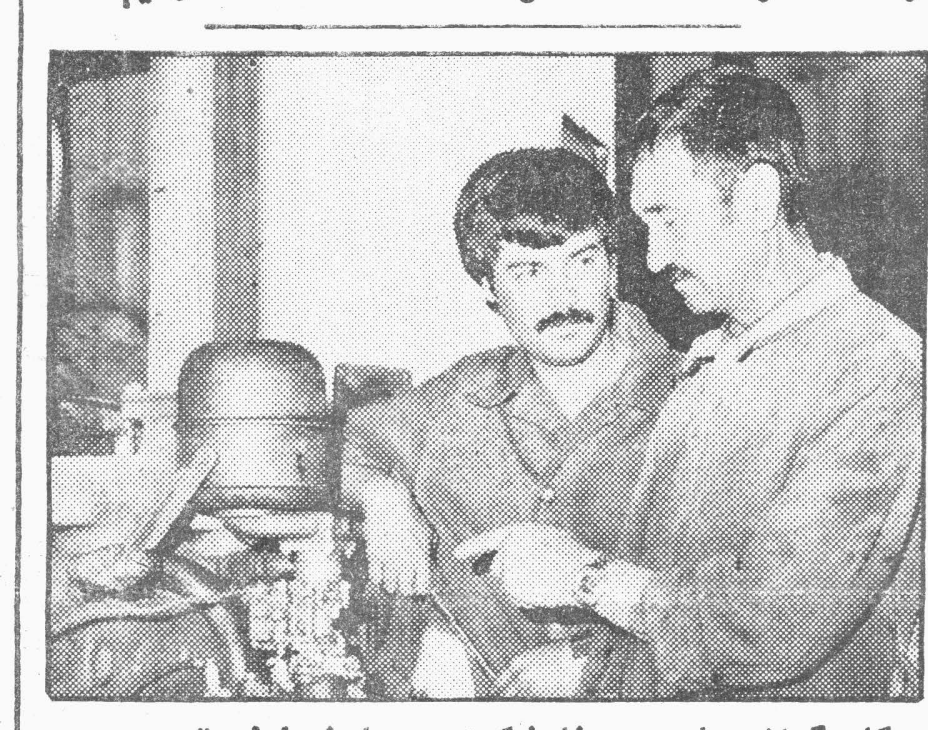

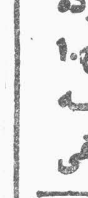
定

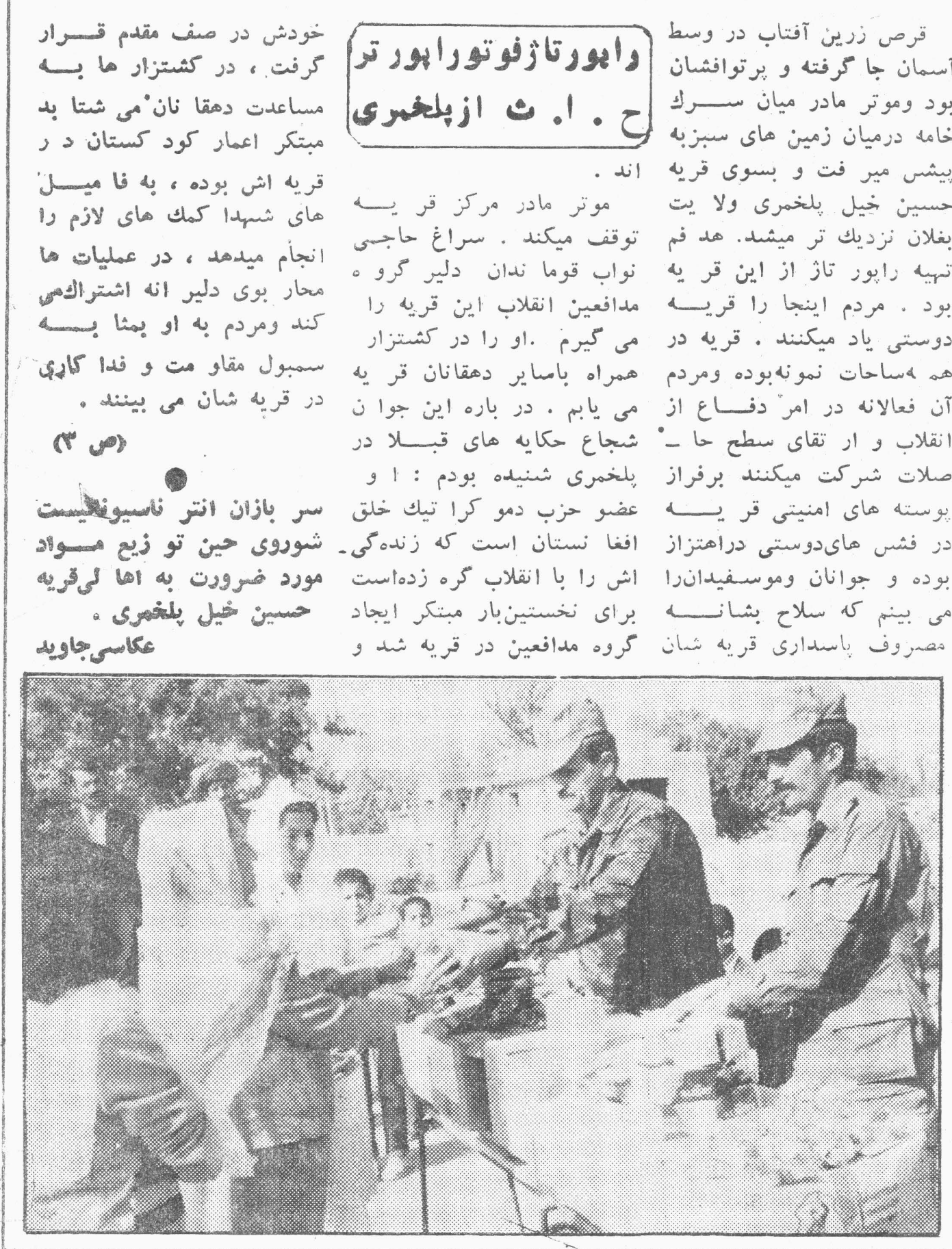

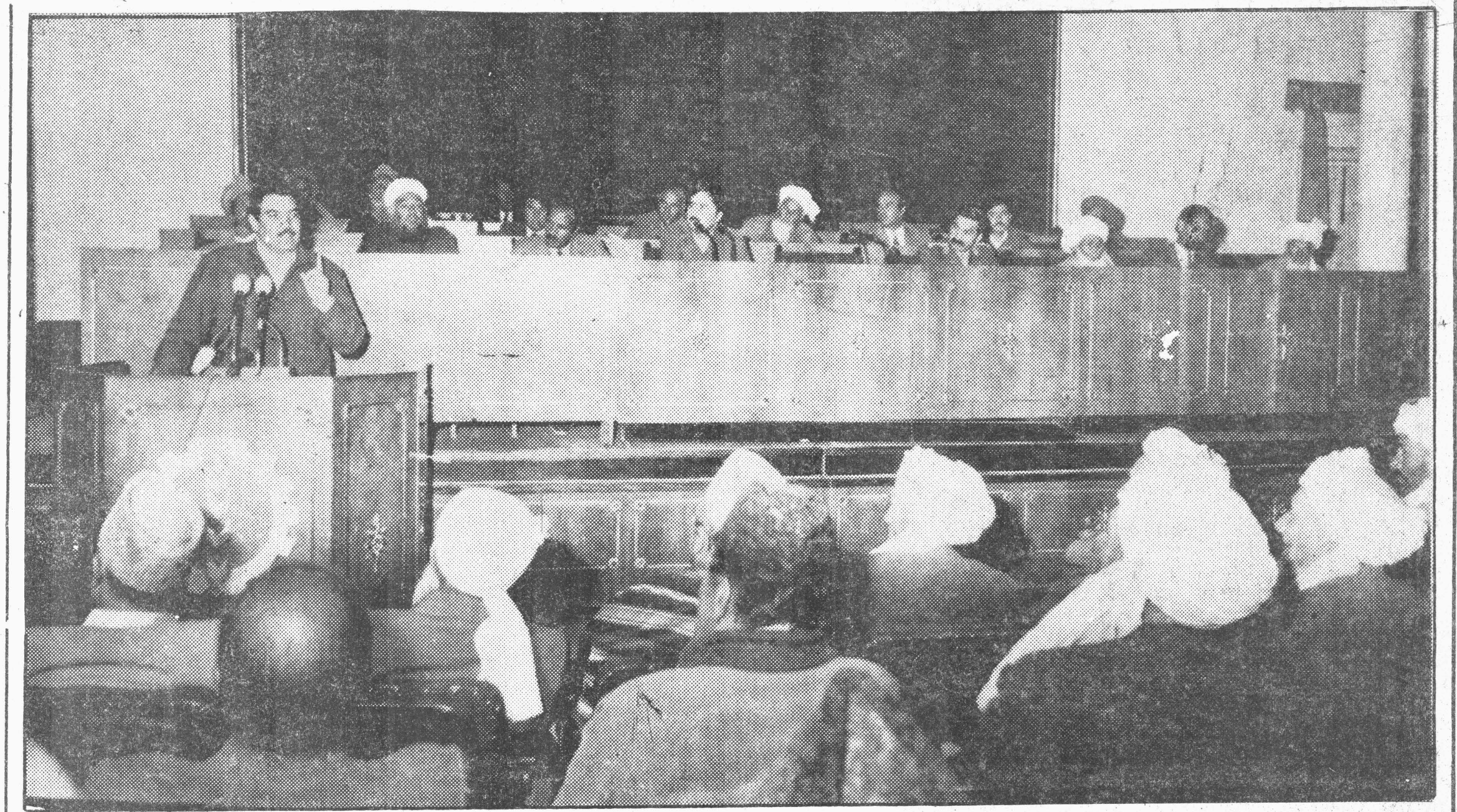

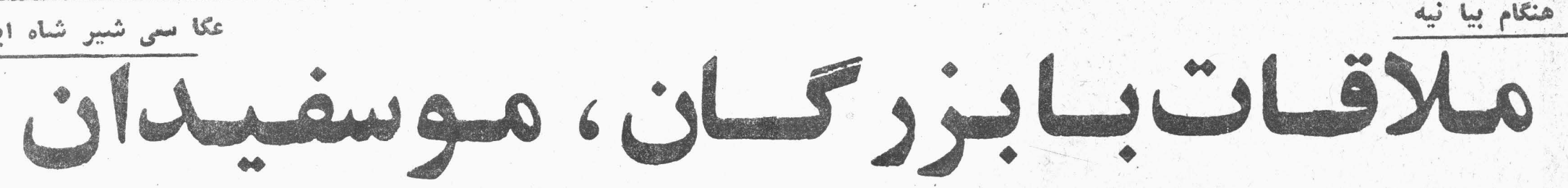

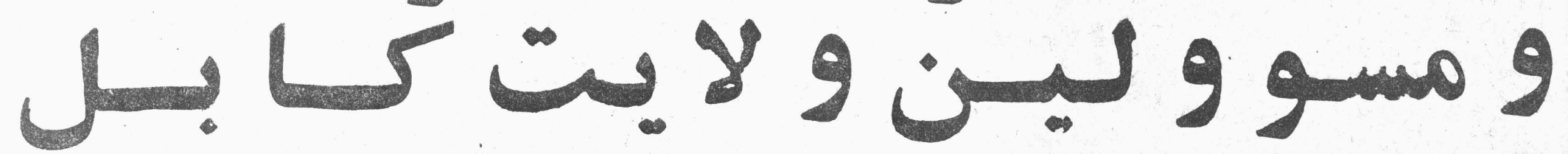

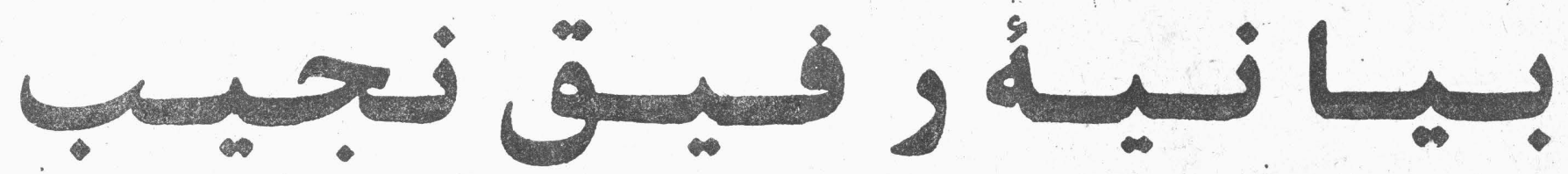

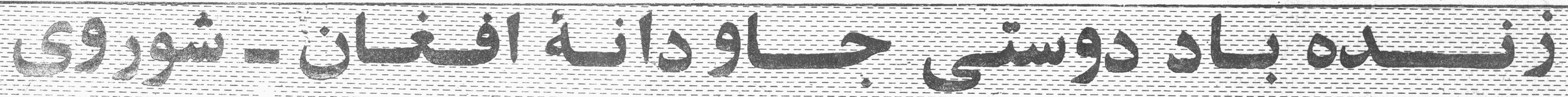




\section{|l L}

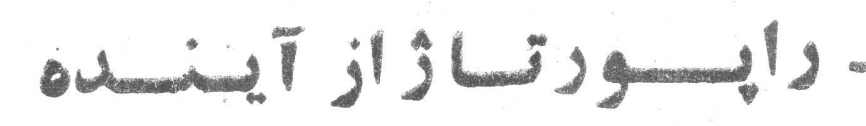 ل}

gon

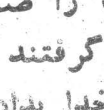
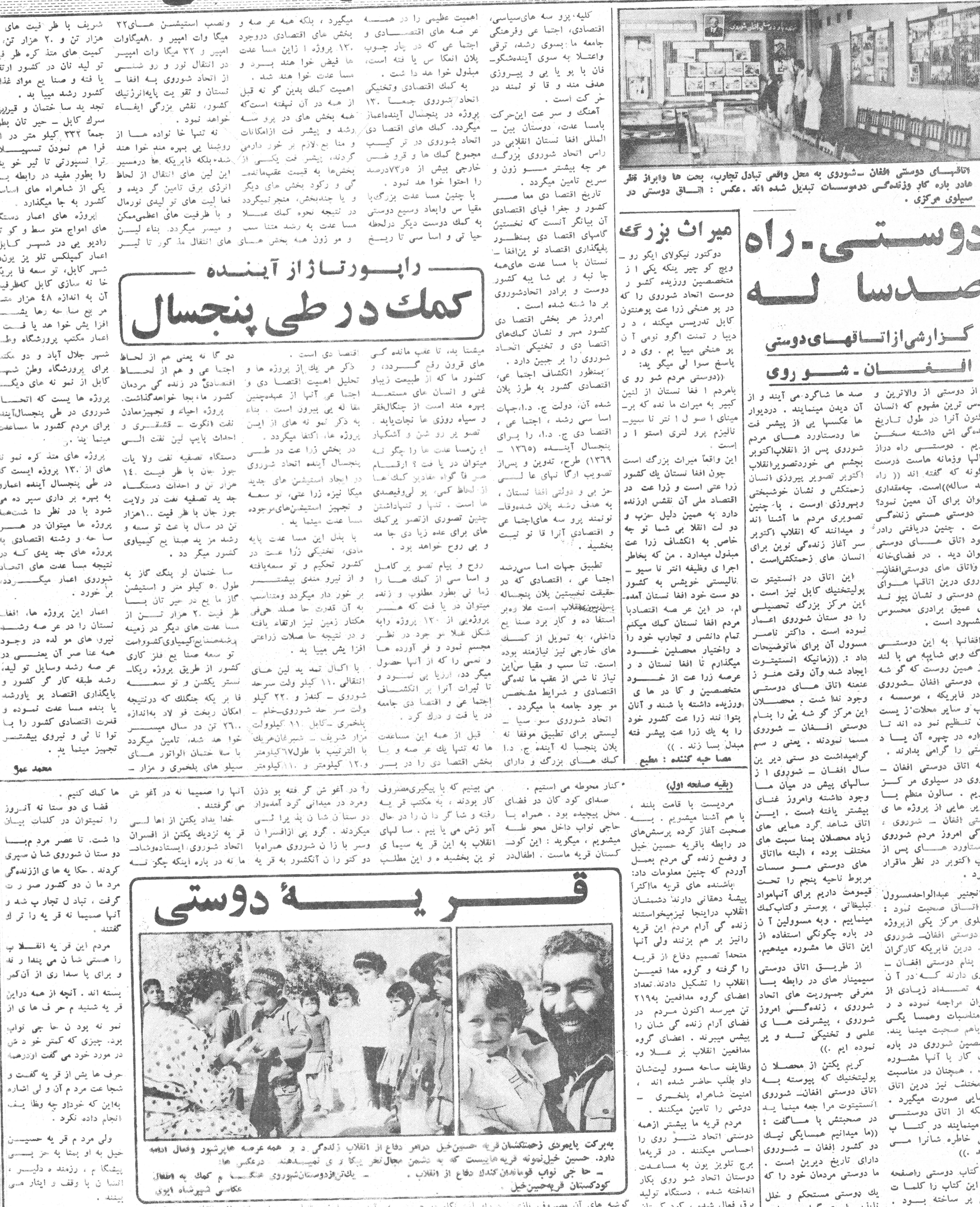

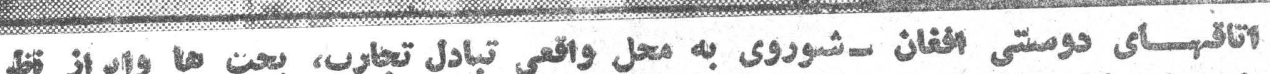

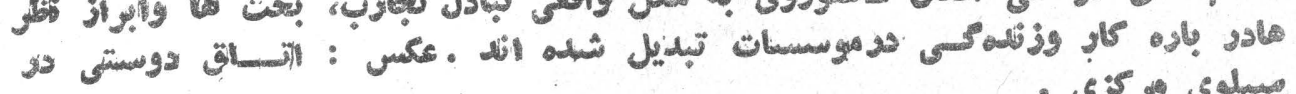

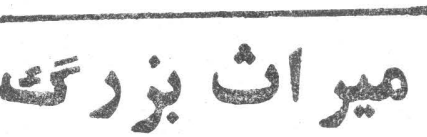

olg-crings d. luble

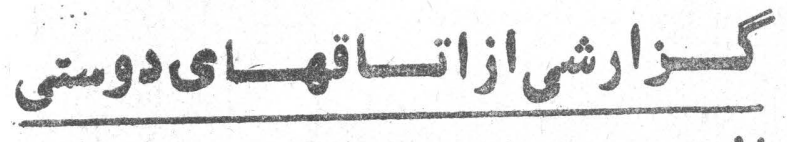

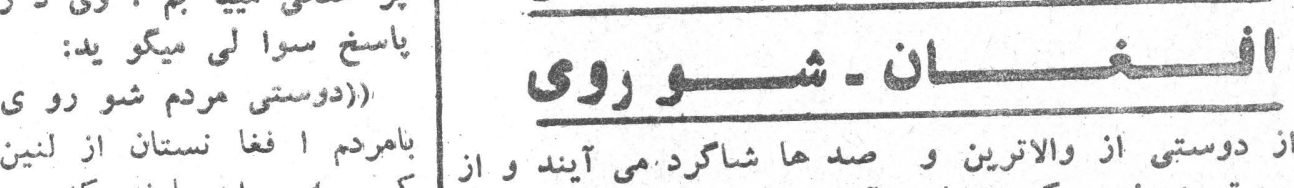

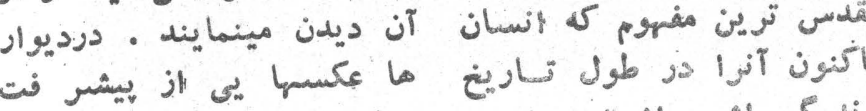

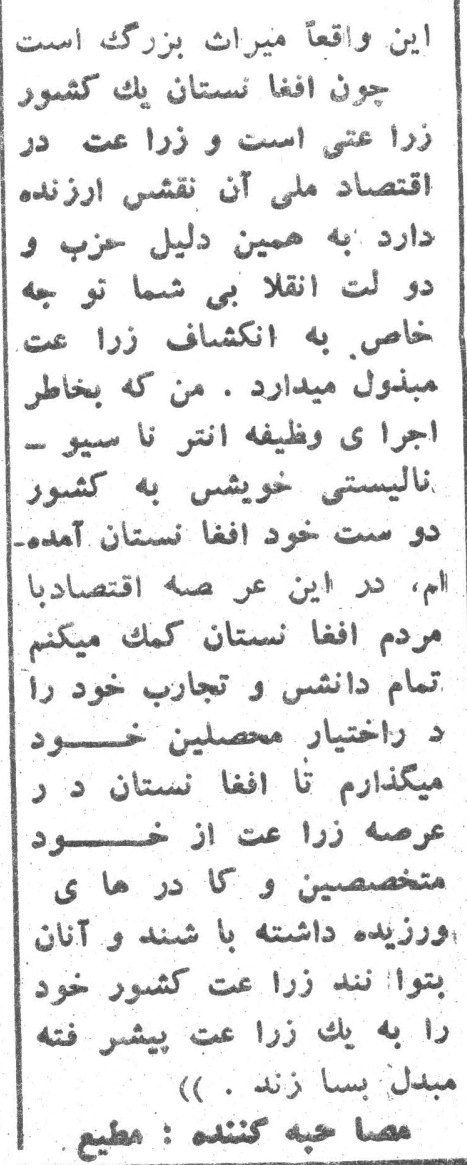
(بقيه صفحه اول)

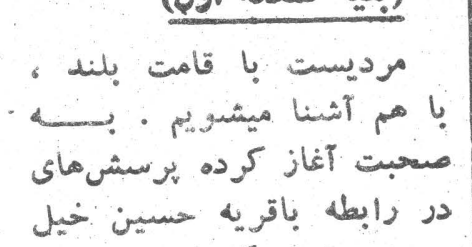


phe ads -

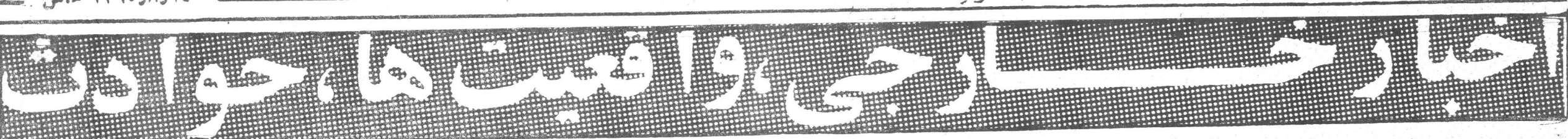
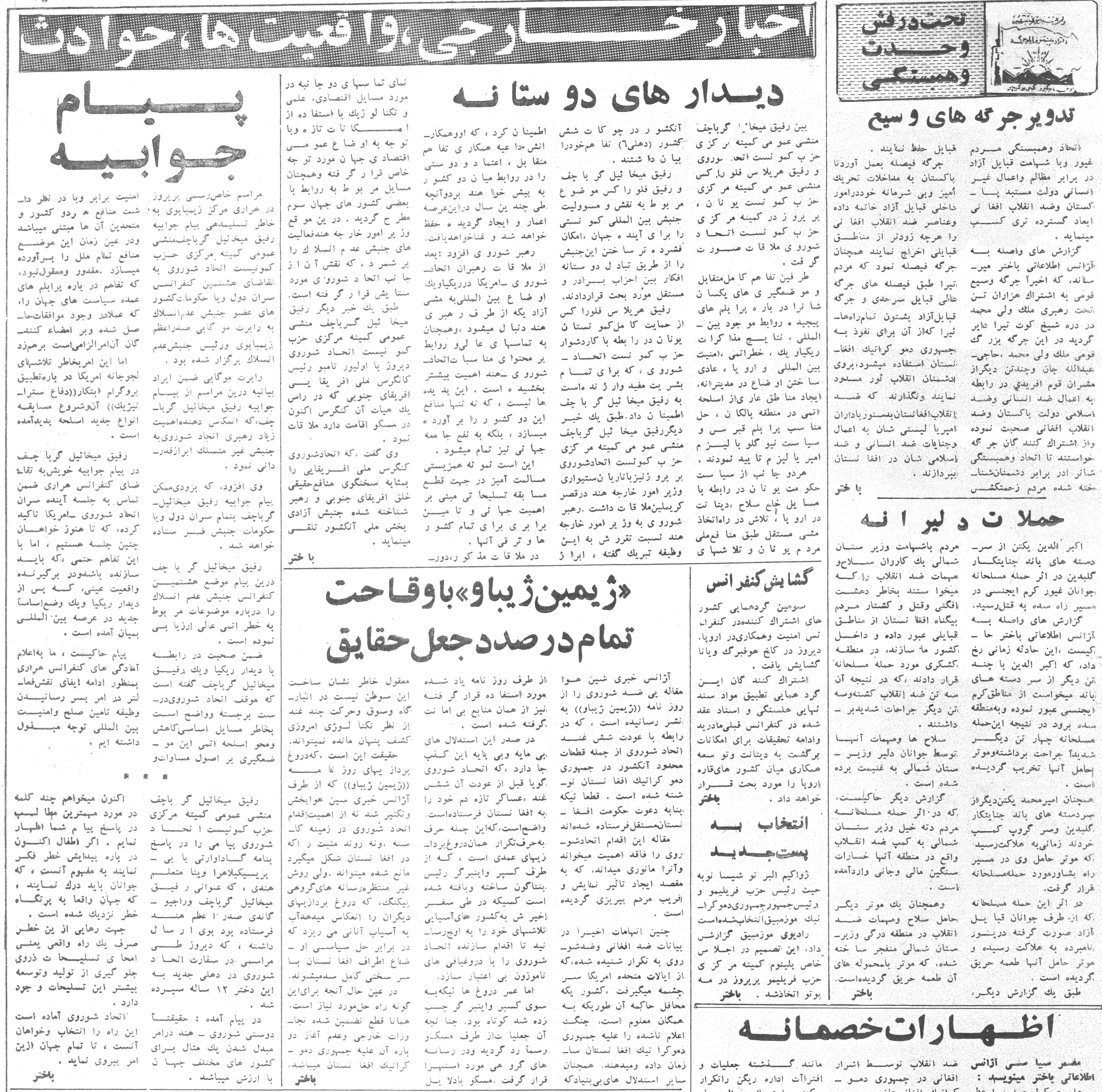

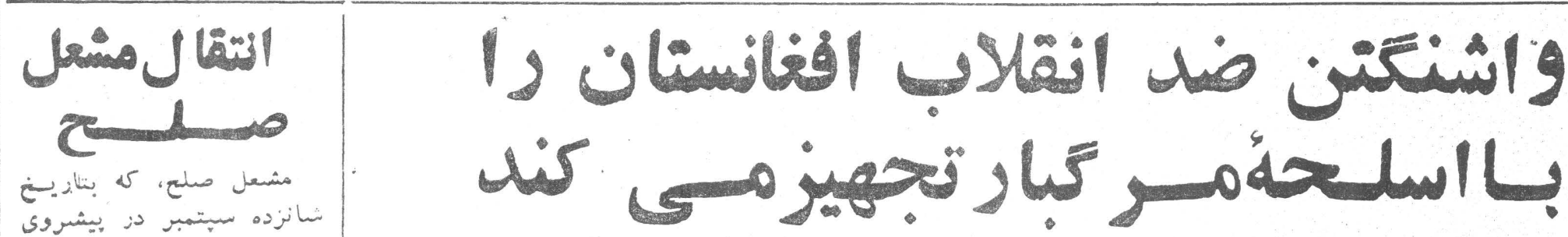

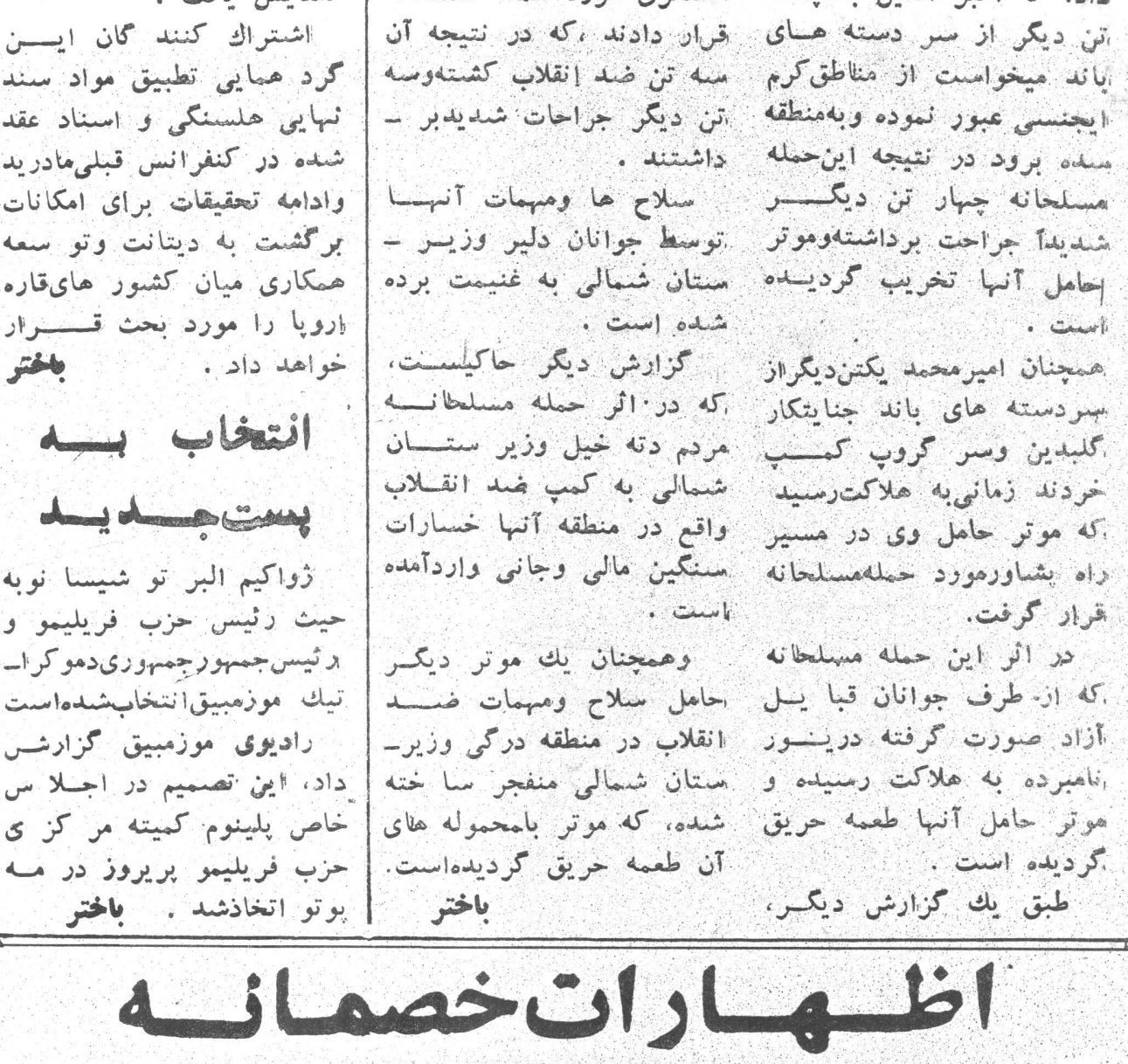

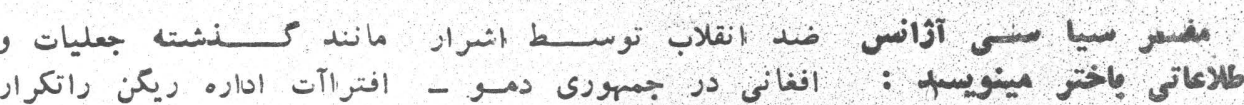
السان

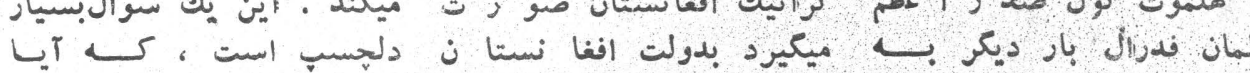

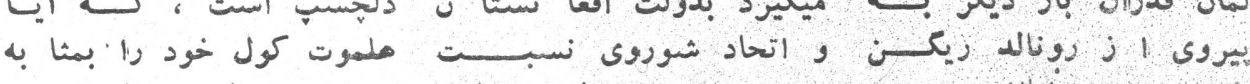

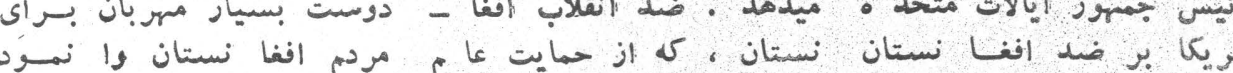

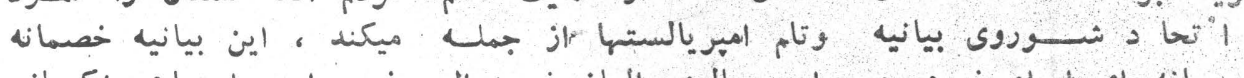

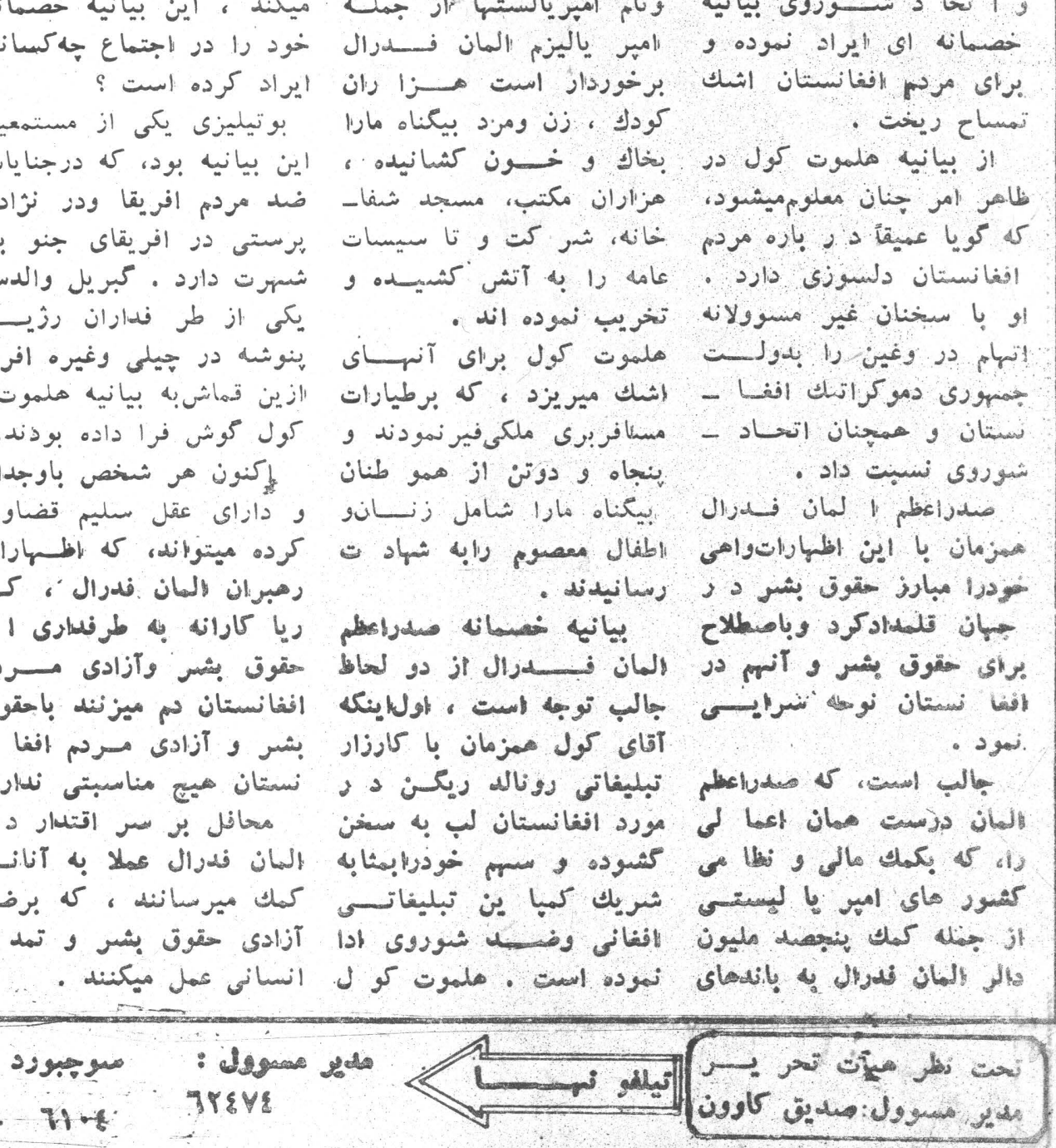

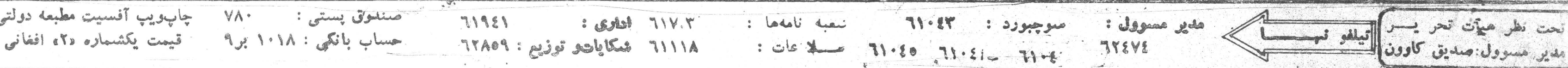

